\title{
Substance-Induced Anxiety Disorder
}

National Cancer Institute

\section{Source}

National Cancer Institute. Substance-Induced Anxiety Disorder. NCI Thesaurus. Code C92623.

An anxiety disorder in which the symptoms of anxiety have been determined to be etiologically related to the direct physiological effects of a substance (i.e., a drug of abuse, a medication, or toxin exposure). 